\title{
ORIGEN DEL PRESIDENCIALISMO CHILENO: REFORMA CONSTITUCIONAL DE 1970, IDEAS MATRICES E INICIATIVA LEGISLATIVA EXCLUSIVA
}

\author{
THE ORIGINS OF CHILEAN PRESIDENTIAL REGIME: THE 1970 \\ CONSTITUTIONAL AMENDMENT, ESSENTIAL PURPOSE OF A BILL \\ AND THE EXECUTIVE EXCLUSIVE LEGISLATIVE INITIATIVE
}

\author{
ARTURO FERMANDOIS VÖHRINGER* \\ José FranCISCO GaRCÍA GARCÍA ${ }^{* *}$
}

\begin{abstract}
RESUMEN: En este trabajo los autores revisitan la reforma constitucional de 1970 que consagró, a su parecer, dos instrumentos cruciales en la supremacía legislativa del Presidente de la República: la iniciativa exclusiva presidencial, y la prohibición de las indicaciones y enmiendas que se aparten de las ideas matrices de un proyecto de ley. Con ello, este trabajo busca demostrar que el presidencialismo chileno no tiene su origen pleno en la Constitución de 1980, sino en la reforma constitucional que se introdujo en 1970 a la Carta de 1925. Asimismo, se analiza cómo la jurisprudencia del Tribunal Constitucional, tanto la del denominado "primer" TC como el actual, ha sido fundamental para consolidar ambos institutos.
\end{abstract}

Palabras claves: derecho constitucional, proceso legislativo, ideas matrices, iniciativa legislativa exclusiva presidencial, Tribunal Constitucional, forma de gobierno, régimen presidencial, presidencialismo.

ABSTRACT: In this paper the authors revisit the constitutional reform of 1970 and argue that it established two crucial devices in terms of legislative authority of the President: exclusive legislative initiative and the prohibition to incorporate amendments that depart from the essential purpose of a bill. Thus, this paper seeks to demonstrate that the Chilean presidential system does not have its origins in the Constitution of 1980, but in the constitutional amendment of 1970, which reformed the Constitution of 1925. Moreover, the analysis includes the role of the jurisprudence of the Constitutional Court (-the so-called first Constitutional Court as well as the present one) in the consolidation of both constitutional devices.

Key words: Constitutional law, legislative process, essential purpose of a bill, executive exclusive legislative initiative, Constitutional Court, governmental regime, presidential regime.

\footnotetext{
* Licenciado en Ciencias Jurídicas Pontificia Universidad Católica de Chile, Máster en Políticas Públicas, Universidad de Harvard. Profesor de Derecho Constitucional, Pontificia Universidad Católica de Chile. Correo electrónico: afermand@uc.cl.

** Licenciado en Ciencias Jurídicas Pontificia Universidad Católica de Chile. Master (LL.M) y Doctorando en Derecho (JSD), Universidad de Chicago. Profesor Investigador Facultad de Derecho, Universidad del Desarrollo. Correo electrónico: jose.garcia@uai.cl
} 


\section{INTRODUCCIÓN}

Se ha hecho habitual en doctrina afirmar que la Constitución de 1980 ideó un régimen presidencialista reforzado, intenso, casi extremo, alejado de nuestras tradiciones del derecho público ${ }^{1}$.

Este trabajo se propone comprobar que dos de los ejes constitucionales más desequilibrantes de ese presidencialismo -la iniciativa legislativa exclusiva presidencial y la protección de las ideas matrices de un proyecto de ley-, fueron en realidad promovidos y consagrados durante el gobierno de don Eduardo Frei Montalva, cuyo acto final de reforzamiento presidencial fue la reforma constitucional de $1970^{2}$.

Estos dos mecanismos están actualmente sometidos a permanente tensión institucional. Ha llegado el momento en que los parlamentarios desean ingresar con sus mociones al terreno económico social, o con sus indicaciones profundizar los prudentes mensajes del Ejecutivo en esas materias.

Es allí donde cobra importancia determinar el sentido y alcance de las normas constitucionales comprometidas, esto es, los artículos $65^{\circ}$ y $69^{\circ}$ de la Carta Fundamental. ¿Qué es una idea matriz de un proyecto de ley? ¿Qué trasfondo tienen las variadas, y a veces anticuadas, materias agrupadas como de iniciativa exclusiva presidencial? Si la Carta reserva como de iniciativa exclusiva al Presidente para determinados asuntos, ¿significa ello que ha dado su salvoconducto de constitucionalidad a todo lo que se legisle en dicho tópico?

Durante 2008, estos asuntos saltaron a primer plano. Primero, con motivo de la discusión y aprobación de la ley No 20.281, conocida como de la "semana corrida", que impuso un alza obligatoria de las remuneraciones para los trabajadores del sector privado, mediante una indicación que aparece alejada de las ideas matrices del respectivo proyecto, sobre salarios base.

Otros ejemplos son los dos proyectos de ley, nacidos como mociones parlamentarias, en el ámbito previsional que, a primera vista, parecen de gran simplicidad. En primer lugar, aquel que busca modificar el DL 3.500 sobre sistema de pensiones, y que establece que las AFP que administren cuentas de ahorro voluntario podrán cobrar por esa administración, una comisión porcentual sobre al saldo de la cuenta y no, como era en la antigua ley, una comisión solo por los retiros que se produjeren. En este sentido, la moción tiene por objeto establecer que esa comisión solo se cobre por el saldo de la cuenta que corresponda a depósitos efectuados a partir de la vigencia de la ley, esto es,

\footnotetext{
${ }^{1}$ José Luis Cea Egaña comenta sobre el presidencialismo chileno: "Cierto es que la comentada tendencia instituida en la Carta Fundamental de 1833, invertida mediante las reformas de 1874 y años siguientes, aunque restablecida en la Constitución de 1925 y sus modificaciones de 1943 y 1970 . Pero, aún así, y reconociendo todo ese proceso, nunca las Constituciones chilenas habían llegado a la hegemonía, formal al menos, del jefe de Estado en los términos con que la traza el actual Código Político" (CEA EGAÑA, 2008, pp. 84-85). A su vez, Humberto Nogueira Alcalá señala: "En la medida que la Constitución hace omisión de este principio de independencia jurídica recíproca entre Ejecutivo y Legislativo, el régimen chileno solo podría ser clasificado en una especie patológica de las formas de gobierno que se ha denominado [presidencialismo autoritario]”. (NOGUEIRA ALCALÁ, 1984, p. 319).

${ }^{2}$ Ley No 17.284, de 1970.
} 
desde el 1 de octubre de 2008 y no sobre el saldo anterior. El segundo proyecto tiene por objeto extender el beneficio de renta vitalicia a ascendientes y descendientes que hubieren vivido con el voluntario bombero fallecido en acto de servicio ${ }^{3}$.

¿Qué tienen en común estas dos iniciativas? Se trata de mociones parlamentarias que transgreden uno de los ejes legislativos que venimos comentando; aquel de la iniciativa exclusiva presidencial en diversas materias, particularmente de impacto económicosocial -y que implique el desembolso de recursos públicos- según lo establece el artículo $65^{\circ}$ de la Carta Fundamental.

¿Cómo se resolvieron estas tensiones? ¿Cómo deben resolverse?

En el origen del presidencialismo, por ejemplo, la iniciativa legislativa exclusiva no es obvia. No es de la esencia de un régimen presidencial. Si se acude al régimen presidencial más clásico, el norteamericano, construido sobre las bases diseñadas por Madison, Hamilton y Jay en El Federalista ${ }^{4}$; la idea de iniciativa exclusiva presidencial en materia legislativa parecería una broma de mal gusto ${ }^{5}$. No es coincidencia que la sección 1 del artículo I de la Constitución norteamericana le entregue "todos los poderes legislativos aquí consagrados" al Congreso ${ }^{6}$.

Pero tanto la iniciativa legislativa exclusiva, así como la prohibición de las indicaciones que se aparten de las ideas matrices del proyecto, están operando en Chile como un reforzador formidable del poder legislativo presidencial.

Esta última, con el objeto de inhibir la presentación de indicaciones inconexas a la problemática central abordada por un determinado proyecto de ley, práctica parlamentaria impropia, y de gran uso en el periodo 1925-1970 que derivaban en las llamadas leyes misceláneas.

Como decíamos, ambos instrumentos del proceso legislativo fueron incorporados a nuestro diseño constitucional en el proceso de reforma constitucional de 1970 a través de la Ley No 17.284, y mantenidos casi sin modificaciones en la Constitución de 1980. Como sostiene Bravo Lira, constituyen parte de una evolución en nuestro régimen político que nace ya en 1924 y finalizaría en los 70 (en particular en 1973 con un nuevo estado de cosas $)^{7}$.

\footnotetext{
3 Se trata de los Boletines No 6102-05 y No 6104-22, respectivamente. Agradecemos estos ejemplos a Pablo Kangiser.

${ }^{4}$ MAdison et al. (1987).

5 Ver en esta materia, por ejemplo, ACKERMAN (1991) y (1989); y KRAMER (2004) y (2001).

${ }^{6}$ Ver GRAFTON (2000).

7 Para este destacado historiador: "Encuadradas dentro de su perspectiva histórica, las transformaciones institucionales del último medio siglo muestran un claro retroceso del esquema que presidió la implantación del régimen de gobierno constitucional en Chile: la dualidad presidente-parlamento (...) El presidente como Jefe de Estado y jefe de gobierno, ha pasado a ocupar un lugar central dentro del régimen. Ha recuperado casi enteramente las funciones legislativas que en el derecho chileno anterior al constitucionalismo fueron parte integrante y muy principal del gobierno. El papel colegislador del Congreso ha sido cada vez más secundario, como lo muestran los mecanismos de iniciativa, de urgencia y veto presidencial y hasta casi nulo, como ocurre en el caso de la legislación delegada, expedida por el presidente mediante decretos con fuerza de ley y, desde luego, en el caso de legislación directa, expedida por el presidente mediante decretos-leyes". Ver BraVo LIRA (1986) p. 180.
} 
En el mismo sentido, el ex Presidente Frei Montalva -quien lideró y consolidó en definitiva el proceso de reforma constitucional de 1970- veía en esta evolución un continuo histórico que nacía en la Constitución de 1925, con la idea de no volver a caer en las prácticas del denominado "periodo parlamentario chileno". La reforma constitucional de 1970, desde la perspectiva de potenciar el arsenal legislativo del Presidente de la República, buscaba corregir aquellas prácticas posteriores a la Constitución de $1925^{8}$.

Así las cosas, el objetivo del esfuerzo reformador de 1970 parecía claro. En una frase, y parafraseando a Edwards, la "fronda" parlamentaria, debía ser domada?.

Parece entonces relevante desempolvar las discusiones y debates que se produjeron en la reforma constitucional de 1970, básicamente aquellas vinculadas a la consagración del aumento del poder legislativo del Presidente de la República, por dos motivos. En primer lugar, para entender el sentido original con que surgen en 1970, en cuanto permiten proyectar ese alcance al momento actual. Y luego, para analizar la jurisprudencia reciente del Tribunal Constitucional, la que ha invocado parte de este debate en fallos relativamente recientes y aludido, en sentencias de 2004 y 2007, ciertos fallos de 1972 emanados del "primer" Tribunal Constitucional. Todo esto ofrecerá una rica línea de continuidad que es necesario mostrar a la dogmática jurídica nacional.

\section{ORIGEN Y SENTIDO CONSTITUCIONAL DE LAS IDEAS MATRICES DE UN PROYECTO DE LEY}

\subsection{REFORMA DE 1970: ORIGEN CONSTITUCIONAL DE LAS IDEAS MATRICES COMO EXIGENCIA A LAS ENMIENDAS A UN PROYECTO DE LEY}

Actualmente, el artículo 69 inciso primero de la Constitución, consagra el respeto a las ideas matrices del proyecto original como limitación para las enmiendas que se incorporen a lo largo del proceso de formación de una ley. En efecto, esta norma dispone:

"Todo proyecto puede ser objeto de adiciones o correcciones en los trámites que corresponda, tanto en la Cámara de Diputados como en el Senado; pero en ningún caso se admitirán las que no tengan relación directa con las ideas matrices o fundamentales del proyecto".

Esta norma, que vino a reiterar una norma similar introducida a la Carta de 1925 por la Ley 17.284 de 1970 -cuerpo legal que realizó modificaciones sustanciales a la Constitución-, nace de la necesidad de que existiera una relación directa entre las indicaciones $-\mathrm{o}$ propuestas de cambios que se presentan durante la tramitación de los proyectos para modificarlos- y las ideas matrices o fundamentales del mismo proyecto de ley.

La importancia de esta conexión "directa" entre las ideas matrices de un proyecto de ley y las enmiendas posteriores que pudieran ser incorporadas en las distintas etapas

\footnotetext{
${ }^{8}$ FREI (1970) pp. 19-52.

9 EDWARDS (1976).
} 
del proceso de formación de una ley; nos llevan a revisar la historia de la Ley 17.284, sus motivos y fines perseguidos.

Como sostiene Silva Bascuñán, la redacción primitiva de la Constitución de 1925 contemplaba, en efecto, en forma explícita, la posibilidad de que un proyecto de ley pudiera ser corregido o alterado por la Cámara revisora, y enunciaba las reglas que, en tal hipótesis, debían observarse. Tomando en cuenta la amplitud de la norma constitucional que lo permitía, fue introduciéndose el hábito de agregar, en el curso de las diversas etapas de gestación, nuevas concepciones y nuevos preceptos al mensaje o moción primitivo; ello provocó vigorosas críticas, en razón de que, por tal vía, un mismo cuerpo normativo incorporaba pluralidad de materias no contempladas al comienzo, a menudo de escasa o ninguna vinculación sustantiva con la proposición inicial. Ello conducía, con frecuencia, a que se alejaran pronunciadamente las normas en definitiva aprobadas de aquellas que propusiera el autor de la moción o mensaje originario. A fin de impedir práctica tan negativa se incorporaron a los reglamentos de las Cámaras preceptos según los cuales "solo serán admitidas (las indicaciones) cuando digan relación con las ideas matrices o fundamentales de un proyecto" (art. 125 del Reglamento de la Cámara de Diputados y art. 101 del Reglamento del Senado ${ }^{10}$.

En el proyecto de reforma constitucional de la Carta de 1925 enviado por el Presidente Frei Montalva en enero de 1969, se introducía como inciso primero del artículo 50 de dicho cuerpo normativo:

"Todo proyecto puede ser objeto de adiciones o correcciones tanto en la Cámara de Diputados como en el Senado; pero en ningún caso se admitirán las que no digan relación directa con las ideas matrices ofundamentales del proyecto".

\subsection{FIN A LAS LEYES MISCELÁNEAS Y BÚSQUEDA DEL DEBATE PARLAMENTARIO}

INFORMADO Y CONTRADICTORIO

El problema de fondo que se buscaba resolver mediante la norma consistía en poner fin a las llamadas "leyes misceláneas", esto es, leyes que contenían regulaciones de los más variados campos sin que exista una relación, ni aun lejana entre ellas.

El primer informe de la Comisión de Constitución, Legislación, Justicia y Reglamento del Senado, de 1 de septiembre de 1969, profundiza en los fundamentos y conveniencia de la reforma en discusión:

"Se trata de elevar a la categoría de norma constitucional lo que ya existe en los Reglamentos del Congreso en relación a las indicaciones de los parlamentarios, ampliando considerablemente el ámbito de aplicación de la norma, que ahora pasa a referirse a las modificaciones, correcciones y adiciones que se introduzcan a los proyectos en los trámites constitucionales del proceso de formación de la ley, y no solo a las indicaciones de los Diputados y Senadores en cada una de las Cámaras

10 SiLVA BASCUÑÁN (2000) p. 117. 
(La Comisión) (...) compartió plenamente la idea contenida en la modificación constitucional en estudio porque con ella se permitirá mejorar notablemente la técnica legislativa impidiendo la aprobación de leyes como ha sucedido hasta ahora que contienen normas sobre numerosas materias que hacen difícil su consulta y engorrosa su aplicación y cumplimiento, dada la falta de correspondencia entre la materia principal, que sirve de título a la ley, y la profusa legislación que contiene sobre asuntos que nada tienen que ver con sus ideas matrices of fundamentales.

Este vicio legislativo debe terminar y con ello desaparecer las llamadas leyes misceláneas' que solo sirven para desprestigiar al Parlamento y su función legislativa"11.

Por su parte, Francisco Cumplido - sin lugar a dudas uno de los actores principales en la discusión doctrinaria de esta reforma- sostuvo en la época que: "La falta de unidad del contenido de las leyes es una demostración cabal de la ausencia o precariedad de la técnica legislativa empleada en su formación. En el lenguaje vulgar, se denomina a estas leyes como "Leyes misceláneas". Es decir, en ellas se regula cualquier materia, tenga o no tenga relación con las ideas fundamentales del proyecto" 12 .

Para Silva Cimma, este vicio del proceso de formación de las leyes demostraba una manifiesta falta de técnica legislativa, y al que se recurría a menudo como consecuencia directa de que se trataba de burlar las restricciones en materia de iniciativa, "introduciendo por la vía de la moción parlamentaria, en un proyecto de ley cualquiera, indicaciones de la más variada índole, absolutamente desconectadas con las ideas y contenido del proyecto primitivo. De esta forma resultaban en definitiva leyes con una tal cantidad de materias inconexas que eran de muy difícil interpretación, siendo tarea ímproba la de detectar en un momento dado qué normas legales estaban vigentes en determinados aspectos. La legislación chilena ha pecado así durante muchos años de falta de precisión, aparte de que las llamadas leyes "de referencia", en que un proyecto hace referencia a otra ley y a veces indirectamente a una tercera, condujeron a la existencia de textos indescifrables, en que se hace difícil determinar la voluntad del legislador"13.

En este sentido, no deja de ser bastante lógico, que las llamadas leyes misceláneas, hayan sido a menudo empleadas en la aprobación de las normas del presupuesto de la Nación ${ }^{14}$.

\footnotetext{
${ }^{11}$ Primer Informe de la Comisión de Constitución, Legislación, Justicia y Reglamento del Senado, de 1 de septiembre de 1969 en PIEDRABUENA (1970) p. 189.

12 Cumplido (1970) pp. 180-181.

13 Silva Cimma (2008) p. 64.

14 En efecto, sostiene el autor: "Esta ley (de presupuesto) que tiene en el Congreso un procedimiento especial de tramitación. Mucho más ágil y que, en estricto rigor, solo puede contener un cálculo estimativo de ingresos y la correspondiente autorización de gasto, resultaba en la práctica antecedida por una cantidad de preceptos más o menos generales, y en algunos casos hasta individuales, de la más variada índole, frecuentemente ajenos al contenido propio de la ley de presupuestos. Muchas veces esos preceptos no solo se limitaban a regular materias nuevas, sino que venían a modificar expresa o tácitamente leyes permanentes, con la agravante de que la ley de presupuestos tenía una duración limitada al año de su aprobación, ya que solo regía ese preciso periodo presupuestario. (...) Si se analizan las sucesivas leyes de presupuesto de
} 
Para Cumplido, esta práctica legislativa, se había consolidado dada la contribución -con igual dedicación-, no tan solo de los parlamentarios, sino también del Ejecutivo: "Los primeros (parlamentarios) logran incorporar a las leyes materias que son de su especial interés y que no han logrado despachar en la legislatura ordinaria, o respecto de las que logran consenso a cambio de apoyar el proyecto principal. Por su parte, el Presidente de la República, usando el veto de adición, plantea al Congreso Nacional la disyuntiva de tener que aceptar o rechazar la forma en que él estima que debe estar regulada una materia, ajena al primitivo proyecto. El Congreso Nacional no puede introducir modificaciones al veto y, generalmente, debe aceptar la proposición del Presidente de la República, o cargar con la responsabilidad de que no haya ley sobre el punto. Indudablemente, ambas conductas son inconvenientes"15.

Es por ello que no debiera sorprendernos que cuando Cumplido fuera a exponer al Congreso -en el seno de la Comisión de Constitución de la Cámara de Diputadosrespecto del sentido profundo del proceso de reforma constitucional en curso sostendría que "se ordena el proceso mismo de formación de la ley al prohibirse la formulación de indicaciones en la sala y al circunscribirse la materia específica sobre la que versa la ley, evitando, lo que es muy común en nuestra técnica legislativa, que un proyecto de ley contenga materias de las más diversas especies, que se han transformado prácticamente en 'proyectos de ley misceláneos', como se les denomina, y que en el fondo no permiten a la ciudadanía una orientación suficiente, impiden un estudio acabado de la institución y parece ser que los resguardos que aquí se adoptan en el proyecto de reforma constitucional satisfacen la exigencia de una técnica legislativa moderna"16.

Para el propio Presidente Frei Montalva, esta iniciativa tenía por objeto la "consagración constitucional de la norma, actualmente contenida en los Reglamentos de ambas Cámaras, pero constantemente violada, de que en un proyecto de ley no son admisibles las indicaciones ni observaciones que no digan relación directa con las ideas matrices o fundamentales del proyecto. Esto pondrá fin al mal hábito de las llamadas "leyes misceláneas", que tratan de toda clase de asuntos, que se prestan al abuso frecuente de que se aproveche una ley importante para introducirle disposiciones destinadas a favorecer a

los últimos veinte años desde 1972 inclusive hacia atrás, se verá que año a año este vicio se había transformado en norma habitual y que también año a año aumentaban los preceptos que, bajo el pretexto de regular materias vinculadas con el presupuesto anual, se referían a las cuestiones más diversas. En los últimos tiempos ni siquiera se guardaba aquella apariencia puesto que el vicio se había institucionalizado". Silva Cimma (2008) pp. 64-65.

15 Cumplido (1970) p. 181. En el mismo sentido, Silva Cimma, reconoce que respecto de esta manera de legislar, justo es reconocer, que echaba mano tanto el Ejecutivo como el Congreso: "Aquél, porque le resultaba un expediente más sencillo para obtener con urgencia las enmiendas de legislación que precisaba y este último, porque sus parlamentarios aprovechaban la necesidad apremiante del Ejecutivo por obtener la aprobación de disposiciones sustanciales para presionar e imponer preceptos destinados a satisfacer intereses electorales. Pero ese era un vicio que ningún bien hacía a los intereses superiores del país. No se trataba simplemente de una deficiente técnica legislativa que se materializaba en la aprobación de leyes formalmente deficientes. Era mucho más que eso. Por esa vía se creaban granjerías y sistemas de privilegio que el Erario debía soportar, así como, en último término, la colectividad toda”. Silva Cimma (2008) p. 65.

${ }^{16}$ Citado por Silva BaSCUÑán (2000) p. 119. 
determinados grupos y aún a personas individuales, y que significan hacer de las leyes una maraña ininteligible para el hombre común y aún difícil de entender por los intérpretes avezados"17.

Así las cosas, el problema de fondo de las denominadas "leyes misceláneas", además de demostrar una defectuosa técnica legislativa, consistía en impedir un debate informado, profundo y técnico de los aspectos esenciales de un proyecto de ley. Así, al establecer el respeto a las ideas matrices evitaba, que en cualquier momento, los parlamentarios introduzcan una materia diversa a la que se estaba discutiendo, lo que abría un nuevo flanco de argumentos y negociaciones sin posibilidad real de analizara el verdadero mérito de la propuesta ${ }^{18}$.

Junto con lo anterior, y como se desprende del fragmento citado de Frei Montalva, esta prohibición buscó además limitar la acción de los grupos de interés durante la tramitación de la ley ${ }^{19}$.

La reforma fue más allá del estado de cosas existentes, exigiendo una conexión entre las ideas matrices y toda modificación, corrección y adición que se introduzca a los proyectos. Con ello se buscaba extender la limitación no solo a las indicaciones introducidas por los parlamentarios, sino también por el Ejecutivo. En este sentido, el Informe de la Comisión de Constitución de la Cámara de Diputados establece que "es interesante destacar que el señor Subsecretario de Justicia, sobre el particular, expresó que la redacción dada al precepto (...) ponía término a la posibilidad del Ejecutivo de introducir por la vía de la observación o veto aditivo, como se denomina en la práctica, toda clase de asuntos, en términos que constituyen un abuso y distorsión del proceso formador de la ley; porque no permite que materia extraña al proyecto pueda ser tramitada conforme al procedimiento normal establecido por la Carta Fundamental"20.

En esta misma línea, en la discusión particular en la Cámara, el diputado Gustavo Lorca expresó que para la historia fidedigna de la discusión de esta enmienda, "deseo dejar constancia de que esto no es solo un impedimento para los parlamentarios, sino también para el colegislador, en el sentido de que no puede formular indicaciones ajenas al proyecto (...)"21.

\footnotetext{
17 Discurso del (1970) pp. 167-168.

18 BUCHHEISTER y SOTO (2005) p. 127.

19 Así lo estima un estudio de Jorge Tapia Valdés, profesor y ex ministro, publicado en 1960. En él critica las leyes misceláneas y expone un caso decidor. La Ley 10.343 -comenta-, se inició con el objeto de conceder un aumento remuneratorio a los funcionarios de la Administración del Estado y terminó en un "verdadero código de heterogeneidades legales" contenidas en 215 artículos permanentes y 100 páginas en el tomo correspondiente de la Recopilación de Leyes. El autor enumera 29 materias que aborda la ley entre las que se incluyen aumento de sueldos; pensiones a los funcionarios afectados por cáncer o tuberculosis; recargo de la cobranza domiciliaria de agua potable; condonaciones de deudas; liberación de impuesto de bienes raíces a ciertas propiedades; creación de escuela de periodismo; liberación de derechos de internación a los ovejunos; modificación de varios impuestos, previsión de los pilotos de la Línea Aérea Nacional, etc. TAPIA (1960) p. 41.

${ }^{20}$ Citado en Cumplido (1970) p. 182.

21 Citado en Cumplido (1970) p. 182.
} 
El debate en la Comisión de Constitución del Senado fue del mismo tenor y llevó a la aprobación, en forma unánime, de un nuevo inciso final en el artículo 53 de la Carta de 1925 sobre veto presidencial en el sentido de que "en ningún caso se admitirán las observaciones que no digan relación directa con las ideas matrices o fundamentales del proyecto" 22 .

Por otra parte, un paso adicional se daría en el proceso conducente a terminar con esta práctica legislativa impropia: la creación del Tribunal Constitucional. En efecto, la reforma proponía que fuera este órgano el que calificara -entre otras cosas y cuando se le solicitara- si la indicación decía o no relación con las ideas matrices. Con ello, se pretendía hacer exigible la prohibición de introducir en un proyecto de ley cambios ajenos a su idea original.

Este paso era relevante, dado que como nos ilustrara Silva Bascuñán, si bien antes de esta reforma tampoco podían admitirse indicaciones contrarias a las ideas matrices - porque lo prohibían los reglamentos de ambas Cámaras-, la inadmisibilidad era declarada por el Presidente de la Comisión o de la Cámara, según sea el caso, quien podía consultarlo con la sala ${ }^{23}$. Este mecanismo daba lugar a interpretaciones amplias del mismo cuerpo político encargado de la tramitación de la ley; así, se producían acuerdos parlamentarios temporales para introducir todo tipo de cambios, sin atender a la norma reglamentaria sobre ideas matrices. Esto fue además expresamente reconocido en el Informe de la Comisión de Constitución de la Cámara de Diputados durante la discusión de esta reforma ${ }^{24}$.

Así, dado que no había modo de hacer exigible la norma ante una instancia independiente al trámite legislativo, "hasta la creación del Tribunal Constitucional en 1970, la exigencia reglamentaria sobre ideas matrices era una mera teoría" 25 .

Finalmente, como cuenta Silva Bascuñán, se debe considerar que en el mensaje del Presidente Frei de 1969 no exigía que la conexión entre indicación e ideas matrices fuera "directa", como fue finalmente aprobado por el Congreso. Explica el constitucionalista:

"La adjetivización "directa"; fue propuesta en el debate sobre la reforma por el diputado Hugo Zepeda Coll, explicando que, si no se agregaba, en el futuro, con un poco de buena voluntad y de manga ancha, pues todas las cosas se relacionan en algo con una disposición legal, perfectamente podría decirse asi: "Concédese un empréstito a la Municipalidad de Peñaflor que no tengan nada que ver con el aspecto económico del empréstito; ¿por qué?, porque lejanamente existe alguna relación con la materia. En esto quiero ser preciso; la relación tiene que ser directa y, en consecuencia, inmediata;

\footnotetext{
22 Cumplido (1970) pp. 189-90 y Silva BASCUÑán (2000) p.118.

23 Silva BASCUÑÁN (1963) p. 177.

${ }^{24}$ Aparece consignado en dicho Informe: "El artículo 125 inciso final del Reglamento de la Cámara establece que solo serán admitidas las indicaciones que se formulen a un proyecto cuando tengan relación con las ideas matrices o fundamentales (...) Esta norma, en el hecho, por ser de rango reglamentario, es burlada en forma reiterada y es asi como a los proyectos se formulan toda clase de indicaciones que los convierte en verdaderas Arcas de Noé, que se denominan vulgarmente leyes misceláneas”. CUMPLIDO (1970) p. 182.

25 BuChHeister y Soto (2005) p. 128.
} 
de tal manera que la disposición legal sea clara. Y cuando uno está frente a una ley que sabe que está frente a una determinada y específica materia" 26.

\subsection{JuRISPRUDENCIA DEL TRIBUNAL CONSTITUCIONAL DE 1972}

Pese a la aparente claridad de los preceptos analizados, y de alguna manera el espíritu de la reforma de 1970; ambos colegisladores, en especial el Congreso, insistieron con "verdadera pertinacia", al decir de Silva Cimma, en la aplicación del sistema de las llamadas leyes misceláneas. Para dicho autor: "Era natural. Se trataba de un vicio tan arraigado en las viejas prácticas parlamentarias y legislativas chilenas, que costaba rectificar los procedimientos tradicional" 27.

El Tribunal Constitucional se pronunció en tres oportunidades durante 1972 sobre esta materia.

\subsubsection{Ley de Presupuesto 1972 (Expediente No1-1972)}

La ley aprobatoria del Presupuesto Anual de la Nación para 1972 es una buena demostración de cómo se perseveró en aquel vicio, contrariando así disposiciones que se habían hecho explícitas en la Constitución Política del Estado. Más de cien disposiciones agregadas en otros tantos artículos, como precedentes a la parte propiamente presupuestaria, fueron el resultado de esa transgresión, a muy poco de haber entrado en vigencia la norma constitucional que categóricamente prohibía ese procedimiento. Ello llevó al Jefe de Estado pedir al Tribunal Constitucional, por vez primera, la declaración de inconstitucionalidad de los artículos 24 a 67, ambos inclusive, del proyecto de ley de presupuesto para 1972 aprobado por el Congreso, tanto por no tratarse de normas presupuestarias, como por no respetar las ideas matrices del proyecto ${ }^{28}$.

En la sentencia de 19 de enero de 1972, recaída en el expediente No 1, el Tribunal acogió en casi su totalidad el requerimiento presentado por el Presidente de la República.

Antes de entrar a la discusión de fondo sobre ideas matrices el Tribunal, contextualiza en el considerando $20^{\circ}$, tanto el rol que le correspondería jugar a este órgano en nuestro sistema normativo; como, indirectamente, referirse a la impropiedad de las prácticas legislativas de las últimas décadas en materia presupuestaria. En efecto, sostuvo:

"Que aun cuando no es posible dejar de reconocer que, históricamente hablando, y en particular desde 1942 en adelante, ha sido costumbre que, año a año, se haya utilizado la Ley de Presupuesto para aprobar las materias más inconexas por todos los Gobiernos y todos los Congresos, sin que hasta ahora se hubiera hecho cuestión constitucional sobre tal procedimiento, pues se impone asimismo destacar que, aparte de que no habia mecanismo para recurrir alegando tal vicio, faltaba también el órgano llamado a emitir ese pronunciamiento. Dicha práctica viciosa se observa aun dentro de la tramitación en el Congreso del proyecto de ley que ha motivado este

\footnotetext{
26 SiLVA BASCUÑÁN (2000) p. 122.

27 Silva Cimma (2008) p. 66.

28 Silva Cimma (2008) pp. 66-67.
} 
requerimiento, ya que un detenido análisis de las indicaciones que los Parlamentarios hicieron en ella, muchas de las cuales obtuvieron aprobación, demuestra que incurrieron en esa práctica personeros representantes de las más diversas corrientes de opinión, todo lo cual permite concluir que se trata de un procedimiento hasta ahora no reparado pero que no puede, obviamente, ser constitutivo de derecho, ya que la doctrina cientifica en materia de derecho público sostiene invariablemente que las prácticas contrarias y la mera tolerancia no pueden provocar la derogación de la norma juridica;" (considerando 20\%) (destacado es nuestro).

Lo anterior no implicaba, en ningún sentido para el Tribunal, una suerte de veto o menoscabo a la labor parlamentaria -en particular a la posibilidad de iniciar proyectos de ley de diversa índole-, sino respetar el proceso de formación de la ley a cabalidad, y sobre todo, tras las enmiendas de 1970. Ello quedó de manifiesto al estimarse en el considerando 22:

"Que lo anterior, claro está, no implica desconocer la facultad que los parlamentarios tienen para iniciar un proyecto de ley en las materias que han sido objeto de requerimiento, pero por la vía ordinaria y siempre que se respeten las limitaciones que la Carta señala, entre otros, en los artículos 45 y $44 N^{\circ} 4$ inciso final. Es decir, que el presente fallo y el requerimiento que lo ha originado, inciden concretamente en la improcedencia de utilizar el mecanismo de la Ley de Presupuesto que es una ley especial para aprobar materias o normativas que exorbitan nitidamente de su contenido en la forma y con los condicionamientos establecidos en los considerandos precedentes;" (considerando 22)

Tras revisar en los considerandos $23^{\circ}$ y $24^{\circ}$ del fallo, el texto constitucional y distintos aspectos de la historia de la reforma constitucional de 1970 en la materia -por ejemplo, los debates al interior de las Comisiones de Constitución de ambas Cámaras, o la posición del ex Presidente Frei Montalva- entra de lleno en los considerandos $25^{\circ}$ y $26^{\circ}$ a delinear que entiende por ideas matrices y los contornos de la misma.

"Que el análisis del texto del artículo 48 conduce a aclarar, desde luego, que el impedimento para que un proyecto pueda ser objeto de adiciones o correcciones dice relación con el concepto de idea matriz o fundamental, dado que, categóricamente; no pueden ser admitidas aquellas adiciones o correcciones que no dicen relación directa con aquella idea. El concepto de idea matriz implica el de generadoras o fundamentales del mismo, vale decir, aquel que imprime carácter y permite definir o concretizar al proyecto de ley de que se trata. Es por eso que, en función de esa idea, el constituyente llega a exigirla de tal manera que impone, aun, que solo se admitirán aquellas adiciones o correcciones que tienen relación directa, es decir inmediata, pertinente o atinente a aquella noción y, en ningún caso, opuesta o ajena a la misma;

Que, en principio, para la determinación de lo que el articulo 48 de la Constitución entiende por idea matriz o fundamental de un proyecto de ley ordinario o común, 
habrá que estarse al análisis de su propio texto, a las justificaciones o comentarios contenidos en el Mensaje o en la moción que lo iniciare, o la discusión, general del proyecto, o, a todo antecedente legislativo de donde aquella se deduzca, que puedan producirse en el primer trámite de la misma. Sin embargo, tratándose de una ley especifica que define o conceptualiza la propia Constitución o una ley, la idea matriz aparece precisada por su esencia en el texto mismo constitucional o legal que la define. Es precisamente el caso de la especie en que es el propio artículo $44 N^{\circ} 4$ del texto constitucional el que se encarga de determinar, complementado por los antecedentes de toda indole que se han indicado en los considerandos precedentes, cual es la idea matriz o fundamental de la Ley de Presupuesto y tal idea no es otra que un cálculo estimativo de entradas y una fijación del monto de gastos. Esta idea que se deduce nitidamente del texto del precepto en análisis se ve todavia confirmada por antecedentes históricos producidos en la discusión del artículo 48 (...)" (considerandos $25^{\circ} \mathrm{y}$ 260) (destacado es nuestro).

\subsection{2 "Aguinaldo de fiestas patrias a trabajadores" (Expediente No 7-1972)}

En fallo de 12 de septiembre de 1972 el Tribunal debia pronunciarse nuevamente sobre la materia.

Como sostiene Silva Cimma, en el requerimiento del Ejecutivo se sostuvo que siendo la ley de aguinaldo de fiestas patrias una iniciativa tendiente a otorgar beneficios a los trabajadores, toda iniciativa que pretendiera extender el beneficio a sectores que no fueran trabajadores, infringía la norma del artículo 48 ya que tal iniciativa se salía del concepto de idea matriz o fundamental ${ }^{29}$.

Sin embargo, el Tribunal no se pronunció sobre este punto, dado que se había acogido la otra inconstitucionalidad invocada por el Ejecutivo, esto es, violación de la iniciativa exclusiva presidencial. En efecto, en su considerando $6^{\circ}$ sostuvo el TC:

"Que debiendo acogerse este primer motivo de inconstitucionalidad planteado en el requerimiento de $f$ s. 1 , lo que impide que se convierta en ley la locución objetada por el Primer Mandatario, no procede entrar a considerar y dar pronunciamiento sobre el otro aspecto que con el mismo fin se invoca en aquel libelo". (considerando 60)

\subsection{3 "Permiso de tráfico aéreo" (Expediente No 9-1972)}

Finalmente, un último pronunciamiento en la materia llegaría en fallo de 26 de octubre de 1972, el cual es relevante para nuestros propósitos, pues sería invocado en 2004 por el TC con ocasión del fallo Jornada Escolar Completa I (STC 410-2004) que será analizado más adelante.

En el expediente número 9, el Ejecutivo volvió a plantear infracciones a la norma sobre idea matriz contenida en el artículo 48 de la Carta de aquella época, con motivo

29 Silva Cimma (2008) p. 76. En efecto, se trataba de extender por parte del Congreso dicho beneficio en los siguientes términos: "como asimismo a todos los campesinos vivientes en los predios sometidos al proceso de Reforma Agraria". 
de un proyecto de ley sobre otorgamiento de de permiso de tráfico aéreo para operar la ruta entre Santiago y las provincias de Aisén y Magallanes, lo que dio pie para que el Tribunal precisar su doctrina en la materia ${ }^{30}$.

En efecto, en el considerando $12^{\circ}$ precisa lo que debe entenderse por idea matriz:

"Que por aceptarse la tesis del requerimiento en cuanto que sea el texto del artículo o precepto legal proyectado que se contiene en una moción o mensaje el que determine por si solo la idea matriz o fundamental del proyecto, ya que no puede prescindirse de considerar el efecto, las razones -causa y propósito, que invoca el autor como inspiradora de su iniciativa para recabar la aprobación del texto que sugiere como norma legislativa en la conclusión de ella. La idea matriz o fundamental está constituida por la situación, materia o problemas específicos que el autor del proyecto de ley señale como existentes y a cuya atención, en todas sus implicancias, quiere acudir por la vía de su potestad normativa legal. La idea matriz es la representación intelectual del asunto que se quiere abordar, es el problema que se desea resolver. Los textos legislativos son los medios o instrumentos hipotéticos para lograr la satisfacción de ese objetivo. Estos medios (artículos de ley, correcciones, adiciones o supresiones), dependen libremente del escogimiento soberano que de ellos hagan y elaboren los autores del proyecto o de las indicaciones respectivas. La única exigencia formal y de técnica legislativa dispuesta por el artículo 48 de la Carta Fundamental, consisten prohibir al parlamentario o al Presidente de la República, como colegislador, sea durante los trámites del proyecto en el Congreso o en el veto (caso del inc. $2^{\circ}$ del Art. 53 de la Constit. Pol. del E.) que introduzcan textos que no vayan dirigidos a abordar el problema o la cuestión substancial que dio origen a la iniciativa legislativa. Asi se explica que pueda darse el caso, sin vulnerar el artículo 48 en examen, que en definitiva la ley no contenga ninguno de los articulos propuestos en la moción o mensaje original y que, sin embargo, por estar las nuevas normas del articulado destinadas a abordar y afrontar la cuestión que lo motivó, dichos artículos sustitutivos guarden relación directa con la idea matriz o fundamental. No es el ropaje de los artículos del proyecto inicial el que fija por sí solo la o las ideas centrales, este es un elemento que debe tenerse en cuenta al examinar la admisibilidad de las indicaciones, pero tiene relevancia la exposición de motivos y, de manera decisoria, la esencia o sustancia del asunto de interés que el legislador autor se ha propuesto encarar y someter a conocimiento, elaboración y aprobación colectiva y final por los cuerpos colegisladores. Debe estarse, entonces, de preferencia al fondo del, y no a las palabras o formas externas. Se trata de confrontar "ideas", concepto abstracto e intelectual, con textos normativos concretos, y no simplemente confrontar unos artículos con otros en su mera naturaleza formal, para decir con arreglo al artículo 48 de la Constitución Política del Estado;" (considerando 120) (destacado es nuestro).

30 Silva Cimma (2008) p. 76. 
En el considerando siguiente, el TC complementará lo anterior, volviendo sobre un punto relevante del primer fallo analizado: la normativa respecto de las ideas matrices o fundamentales de un proyecto de ley, y el que las enmiendas al mismo deban enmarcarse y ajustarse al "problema que se desea resolver"; no busca entorpecer ni menoscabar la labor parlamentaria, simplemente busca terminar con algunas prácticas impropias del pasado. En este sentido, el tribunal sostiene:

"Que, lógicamente, debe, por consecuencia, declararse que dada la amplia discrecionalidad de la función legislativa para crear y concebir las reglas sociales obligatorias, abstractas, impersonales y generales, sin más limites que los que emanan del texto constitucional, no es posible, en razón del articulo 48, rechazar las correcciones o adiciones que se hagan a un determinado proyecto, mediante un mero proceso subjetivo de calificación acerca de las bondades, deficiencias o inconvenientes que se le atribuyan. Los cuerpos legislativos se pronuncian por la aprobación o rechazo de ellos, mas no privan a la autoridad de su facultad inalienable y consustancial con su investidura para proponer la norma que les parezca adecuada. Únicamente en el caso de que se trate de introducir regulaciones ajenas a la idea central del proyecto, determinada jurídicamente como se ha hecho, que no tengan relación directa con la idea matriz o fundamental, en los términos ya señalados para su jurídico establecimiento, aquellas serán inadmisibles por razón de lugar y de oportunidad. Este Tribunal, por cierto, tampoco tiene jurisdicción para entrar a juzgar la admisibilidad, en función de los resultados que se persigan, se obtengan o se malogren, no es propia de su juzgamiento y nada tiene que ver con la limitación que contempla ese precepto constitucional;" (considerando 130).

\subsection{LA DISCUSIÓN HOY: JURISPRUDENCIA DEL TRIBUNAL CONSTITUCIONAL EN CASO RPA (2007)}

Desde la década de 1990, la doctrina y el Tribunal Constitucional han tenido ocasión de analizar el tema en numerosas ocasiones. El Tribunal, por ejemplo, ha profundizado sus alcances y entregado nuevos criterios de interpretación con el ánimo de dar certeza al momento de interpretar la disposición e iluminar su aplicación en la discusión legislativa ${ }^{31}$.

En el último tiempo han destacado tres fallos, que creemos han sentado una jurisprudencia sólida en la materia. Los dos primeros fallos del Tribunal Constitucional a los que hacemos referencia se pronunciaron en 2004 (Jornada Escolar Completa I y II), frente a sendos requerimientos en los que se alegaba la inconstitucionalidad de materias que, si bien fueron aprobadas en el Congreso, eran a juicio de los requirentes contrarias a las ideas matrices del proyecto original ${ }^{32}$.

\footnotetext{
${ }^{31}$ Un ejemplo de esto es la STC Rol No 259 (26 de septiembre de 1997).

32 La primera sentencia decide el requerimiento presentado por un grupo de Diputados alegando la inconstitucionalidad de una serie de normas del proyecto que modificaba la ley de Jornada Escolar Completa y otros cuerpos legales (llamado Caso Jornada Escolar Completa I) STC Rol N 410 (2004). En el
} 
En junio de 2007, el Tribunal Constitucional consolidó su jurisprudencia en la materia mediante un tercer pronunciamiento. Esta vez un grupo de diputados presentó un requerimiento al Tribunal solicitando que se declarara contrario a la Carta Fundamental, una indicación presentada por el senador Hernán Larraín en la tramitación de un proyecto de ley que introducía modificaciones a la legislación sobre responsabilidad penal adolescente ${ }^{33}$.

Resumiendo su jurisprudencia, y tras analizar de manera previa que debe entenderse por "indicación" ${ }^{4}$, sostuvo el Tribunal en el considerando $17^{\circ}$ que se debe entender por idea matriz o fundamental del proyecto:

“(...) en sentencia de 26 de enero de 2007, Rol No 719, este Tribunal reiteró lo ya expresado en sentencia de 26 de septiembre de 1997, Rol $N^{\circ} 259$, en cuanto a las ideas matrices of fundamentales del proyecto (...) se las ha caracterizado como las "que le sirven de sustentación de base (a un proyecto) y en las cuales se apoyan otras ideas pero de carácter secundarias o derivadas". (...) "La exigencia de que las indicaciones digan relación "directa" con las ideas matrices o fundamentales del proyecto, merece, igualmente, cualificarse: "El concepto de relación directa es antagónico en la historia de la Reforma al concepto opuesto o ajeno; es decir, la relación debe ser próxima, cercana, pertinente o atinente a las ideas del proyecto". (considerando $17^{\circ}$ )

Continúa el Tribunal preguntándose acerca de dónde deben estar contenidas las ideas matrices o fundamentales del proyecto. Para el Tribunal:

“(...) la preceptiva contenida en la Ley No 18.918, Ley Orgánica Constitucional del Congreso Nacional, dio respuesta definitiva a esta interrogante, que con anterioridad habia preocupado a la doctrina" agregando que "en efecto, el inciso final

segundo fallo (llamado Caso Jornada Escolar Completa II), un grupo de 15 senadores acudió al Tribunal para que declare inconstitucional las normas contenidas en el mismo proyecto de ley que exigían la concursabilidad de los cargos de los Directores de Establecimientos de Educación y Jefes de Departamento de Educación Municipal -concursabilidad que sería necesaria para poder conservar sus puestos-. STC Rol $\mathrm{N}^{\circ} 413$ (2004).

33 Caso llamado "Ley de Responsabilidad Penal Adolescente", STC Rol Nº 786 (2007).

34 En el considerando $16^{\circ}$ sostiene: "La doctrina de los iuspublicistas ha entendido que las adiciones o correcciones que los órganos colegisladores pueden introducir a un proyecto de ley durante su tramitación configuran lo que, genéricamente, se conoce como "indicaciones". Así, el profesor Alejandro Silva Bascuñán sostiene que "el uso de la palabra (indicación) da a entender que se refiere al texto en el cual se formaliza cualquier tipo de proposición que parte del supuesto de un documento anterior, mediante la cual se insta por una adición, supresión, modificación o corrección de cualquiera naturaleza". (Tratado de Derecho Constitucional. Tomo VII. Editorial Jurídica de Chile, 2000, p.122) (...) Por su parte, la jurisprudencia de este Tribunal ha precisado que "la voz "indicación", referida a un proyecto de ley, comprende para la técnica legislativa, toda proposición tendiente a corregir o adicionar un proyecto durante la etapa de su discusión y aprobación". (Sentencias Rol No 259, considerando 16 , y Rol No 719, considerando 210). Congruente con lo expresado, el artículo 24, inciso primero, de la Ley No 18.918, Orgánica Constitucional del Congreso Nacional, precisa que "solo serán admitidas las indicaciones que digan relación directa con las ideas matrices o fundamentales del proyecto". 
del artículo 23 de la Ley $N^{\circ}$ 18.918, antes citada, expresa: “...se considerarán como ideas matrices o fundamentales de un proyecto aquellas contenidas en el mensaje o moción, según corresponda", lo que reafirmó con la cita pertinente del inciso primero del artículo 24 del referido cuerpo legal referido a que "solo serán admitidas las indicaciones que digan relación con las ideas matrices o fundamentales del proyecto ...". (...) Precisando aun mejor, esta Magistratura ha decidido que la expresión "idea matriz o fundamental" que emplea la preceptiva constitucional "está constituida por la situación, materia o problemas especificos que el autor del proyecto de ley señale como existentes y a cuya atención, en todas sus implicancias, quiere acudir por la vía de su potestad normativa legal. La idea matriz es la representación intelectual del asunto que se quiere abordar, es el problema que se desea resolver...". (Sentencia de 26 de octubre de 1972, Expediente $N^{\circ}$ 9, considerando $12^{\circ}$ ) (...)" (considerando $17^{\circ}$ )

Complementando su análisis, el Tribunal vuelve sobre un punto central del análisis: ¡cuál es el fin de esta normativa? En este sentido, el Tribunal sostiene:

"Complementando lo ya reseñado, en sentencia Rol No 413 se recordó que la exigencia constitucional de que las indicaciones formuladas a un proyecto de ley respeten las ideas matrices o fundamentales del proyecto fue establecida con el propósito de eliminar los llamados "proyectos misceláneos". En esa misma oportunidad esta Magistratura sentó la tesis de que se debe evitar caer en el extremo opuesto de rigidizar el sistema impidiendo que, por la vía de las indicaciones, se enriquezca la iniciativa original, propósito básico que deben perseguir los órganos colegisladores en su función primordial de crear normas claras, sistemáticas y coherentes en beneficio de la certeza juridica (considerando 330)". (considerando $\left.17^{\circ}\right)$.

Cierra el Tribunal, sosteniendo que en definitiva,

“(...) las ideas matrices of fundamentales del proyecto son unicamente las comprendidas en el mensaje o moción pertinente y las indicaciones que tienen relación directa con las mismas son las que guardan con las primeras no solo una vinculación inmediata sino que, además, sustantiva". (considerando $17^{\circ}$ )

Para el TC, la Constitución busca entonces que las enmiendas a un Proyecto sean analizadas con detención y en su contexto, tanto por los poderes del Estado como por los interesados, todos asistentes al proceso de formación de la ley. Cualquiera sea el mérito de la norma, lo adecuado es permitir la existencia de un debate profundo. Las indicaciones contrarias o que no tienen relación directa y sustantiva con las ideas matrices rompen esta regla y abren la posibilidad a que en el trámite legislativo los cambios legales no se sometan los estándares de contradicción y contraargumentación debidos. 


\section{INICIATIVA LEGISLATIVA EXCLUSIVA PRESIDENCIAL}

Las materias de iniciativa exclusiva del Presidente de la República son aquellas que solo pueden transformarse en ley si el Presidente de la República resuelve enviar el Mensaje respectivo al Congreso (art. 65 CPR). El constituyente desea que todas las leyes que tengan un impacto económico en la vida nacional, sean iniciadas por quien tiene a su cargo "el gobierno y la administración del Estado", quien es el Jefe del Estado: el Presidente de la República (art. 24). Como veremos, el texto actual del artículo 65 de la Carta proviene de una tensa evolución histórica y constitucional entre presidentes y congresos, que tuvo lugar por más de 45 años.

\subsection{EVOLUCIÓN DE LA INICIATIVA EXCLUSIVA GENERAL DESDE LA CARTA DE 1925}

\subsubsection{Los intentos de reforma constitucional entre 1925 y 1969}

Desde la promulgación de la Constitución de 1925 y a través de sus reformas por las leyes números 7.727 de 1943 y 17.284 de 1970, se fueron otorgando facultades al Jefe de Estado para asumir la más plena responsabilidad en el manejo administrativo, financiero, tributario y presupuestario del país. La intensificación de las críticas, formuladas con creciente vigor por la opinión pública y principalmente por los voceros del Ejecutivo, acerca de la irresponsabilidad con que actuaría el Parlamento al extender los compromisos del Estado y al despachar cuerpos normativos que no estaban debidamente financiados, se tradujo, accediendo a la presión de los grupos y de los intereses económicos, en la ampliación que, desde la promulgación de la ley 17.284 de 1970, se dispuso en materia de iniciativa presidencial, ratificada por la Carta de $1980^{35}$.

En 1943, la primera reforma a la Constitución de 1925 incorporó una serie de materias de iniciativa exclusiva del Ejecutivo; nace ella del desorden administrativo y económico siguiente a la entrada en vigencia de esa constitución.

Como relata Silva Bascuñán, fue atribuido en amplios sectores de la ciudadanía a las iniciativas de los congresales, que, según sus críticos, se veían obsesionados por afanes demagógicos de conquista del electorado y se mostraban despreocupados de la suerte de los negocios del Estado y de sus finanzas. Dice el tratadista: "La convicción de que, privando de derecho de iniciativa a los representantes populares en los órdenes administrativos y financiero, se daría un gran paso para su fortalecimiento, fue la idea central que inspiró la primera reforma de que fue objeto el texto de 1925. Mediante la ley 7.727, de 23 de noviembre de 1943, en efecto, impulsada vigorosamente por el Presidente Juan Antonio Ríos y por su Ministro de Justicia Oscar Gajardo Villarroel, se restringió la iniciativa parlamentaria en materia de gastos públicos, reservándose con exclusividad al Presidente las materias indicadas en el inciso $3^{\circ}$ agregado al artículo $45^{\prime \prime} 36$.

En efecto, el Ministro de Justicia de la época sintetizaba el núcleo central del debate ante la Cámara de Diputados:

35 SilVA BASCUÑ́́N (2000) p. 200.

36 SILVA BASCUÑÁN (2000) p. 107. 
"Si el factor económico es determinante para el éxito de un Gobierno, y por lo tanto para la felicidad de la ciudadanía, la marcha de las finanzas solo puede ser acertada cuando su dirección esté en una sola mano. La Constitución de 1925 trató de establecer un Ejecutivo fuerte, pero no advirtió que al planificar dentro de ella un sistema financiero débil, en que interfiere cada diputado y cada senador, su propósito resultaba estéril por la libre e ilimitada actual iniciativa parlamentaria en materia de gastos públicos. (...) El Ejecutivo se ve obligado a compartir la facultad administrativa con el Congreso (...) y ni el Ejecutivo no el Congreso pueden llenar a conciencia su papel (...) El segundo, en los últimos 40 años, ha empleado la mayor parte de sus actividades, las está empleando aún hoy en ajustar y reajustar sueldos, y el primero no ha podido, con excepción de contados lapsos, entrabados por esas circunstancias, imprimir el progreso del pais la aceleración metódica que reclama"37.

Para el secretario de Estado, la falta de iniciativa exclusiva presidencial en materia legislativa en aquellas materias que irrogaran gastos fiscales, había sido la gran deuda de la Constitución de 1925. La falta de esta:

"ha dado vida a la inestabilidad en la organización administrativa; ha llevado al embate politico lo que es de la elemental técnica del Gobierno; ha permitido alterar la contextura legitima de los servicios públicos, entregándolos a las influencias indebidas de la politiquería, bajo la presión irresponsable de las clientelas electorales; ha roto el orden de las finanzas y el equilibrio de los presupuestos, y ha quitado al Ejecutivo, en la gestión financiera, toda la autoridad que le es debida en razón de las supremas conveniencias nacionales; en una palabra, ese vacio es la mantención de las iniciativas en materias de gastos públicos"38.

Más adelante, sería el Presidente Jorge Alessandri quien trataría una vez más de aumentar las facultades del Presidente de la República en esta materia. En el Mensaje con el cual envió el 24 de julio de 1964 al Congreso Nacional su proyecto de reforma constitucional, expresó:

"Aquellas prácticas inconvenientes que antes ejercitó el Congreso en la ley de Presupuestos, se hace sentir hoy en día en todos los proyectos que el Ejecutivo somete a su consideración, especialmente en los de orden social, previsional, financiero, tributario y otros, aparte de que muchas veces los parlamentarios toman directamente la iniciativa de proyectos de ley sobre estas materias, que producen efectos aún peores. Cada proyecto es objeto de cientos de indicaciones que desnaturalizan su finalidad, que destruyen otras legislaciones vigentes y que involucran toda clase de materias absolutamente ajenas al proyecto mismo (...) Las consecuencias de todas estas iniciativas-continuó diciendo el señor Alessandri- $y$ de los errores que puedan significar recaen sobre el Presidente de la

\footnotetext{
37 Óscar Gajardo citado por FrEI (1970) p. 37.
}

38 Óscar Gajardo citado por FrEI (1970) p. 37. 
República, a quien corresponde la administración financiera y económica de la Nación. Si este tiene la responsabilidad exclusiva de su manejo, lo lógico es que los parlamentarios no tengan derecho alguno de iniciativa en esta materia y que ella le pertenezca exclusivamente al Jefe de Estado"39.

El proyecto enviado por su sucesor, Eduardo Frei Montalva, el 30 de noviembre de 1964, contiene una proposición análoga aunque más restringida que la aconsejada por el señor Alessandri. Este proyecto de reforma, que fuera detenido en el Senado, fue sometido al examen de una Comisión especial, en la cual no se alcanzó a analizar específicamente el punto ${ }^{40}$.

\subsubsection{La reforma constitucional de 1970}

En la segunda amplia iniciativa enviada el 17 de enero de 1969 por el Presidente Frei Montalva se expresaron, en su exposición de motivos, criterios similares a los desarrollados en 1964:

"La autoridad del Ejecutivo debe ser reafirmada en lo que concierne a la planificación del desarrollo y del control del proceso económico y, para este efecto, es necesario extender los proyectos de iniciativa exclusiva del Presidente de la República, a todas las materias que incidan en los gastos fiscales y en el régimen de remuneraciones $y$ de previsión del sector privado. La idea tiene ya un lugar en la Constitución vigente, donde la llevó una reforma que patrocinó el Presidente Ríos. Pero su texto, la interpretación que de ella se ha dado y la experiencia recogida, hacen impostergable ampliarla en la forma que propugna. Es imperioso porque la eficacia de la gestión económica del Estado, a la que están ligados todos los sectores de la Nación, hace inevitable radicar esta responsabilidad en el Poder Ejecutivo, el que, por su estructura y la asistencia técnica de que dispone, está en situación de actuar con la coherencia y la continuidad que el Congreso Nacional no puede dar y que son esenciales en todos los paises, pero especialmente en los que están en desarrollo como el nuestro" 41.

En definitiva, la ley 17.284 de 1970 dispuso claramente aquellas materias en las que el Presidente gozaría de iniciativa exclusiva:

"Corresponderá exclusivamente al Presidente de la República la iniciativa para proponer suplementos a partidas o item de la Ley General de Presupuestos; para alterar la división politica o administrativa del pais; para suprimir, reducir o condonar impuestos o contribuciones de cualquier clase, sus intereses o sanciones, postergar o consolidar su pago y establecer exenciones tributarias totales o parciales; para crear nuevos servicios públicos o empleos rentados; para modificar las remuneraciones y demás beneficios pecuniarios del personal de los servicios de la administración del estado, tanto central

\footnotetext{
39 SILVA BASCUÑÁN (2000) p. 109.

40 SilVA BASCUÑÁN (2000) p. 109.

41 Piedrabuena (1970) p. 155.
} 
como descentralizada; para fijar los sueldos o salarios minimos de los trabajadores del sector privado, aumentar obligatoriamente remuneraciones y demás beneficios económicos o alterar las bases que sirven para determinarlos; para establecer o modificar los regimenes previsionales o de seguridad social; para conceder o aumentar, por gracia, pensiones $u$ otros beneficios pecuniarios, y para condonar las sumas percibidas por concepto de remuneraciones $u$ otros beneficios económicos, pensiones de jubilación, retiro o montepio o pensiones de gracia. No se aplicará esta disposición al Congreso Nacional y a los servicios que de él dependan”.

"El Congreso Nacional solo podrá aprobar o rechazar, o disminuir en su caso, la modificación de la división politica o administrativa, los servicios o empleos y los beneficios pecuniarios a que se refiere el inciso anterior"

\subsection{INICIATIVA ECONÓMICA EXCLUSIVA: FIN A LAS INDICACIONES O INICIATIVAS PARLAMENTARIAS QUE DISTORSIONAN COHERENCIA GLOBAL DEL SISTEMA ECONÓMICO}

Los autores de la época respaldan la reforma constitucional de 1970, principalmente porque impide a los parlamentarios alterar la coherencia global del sistema económicosocial. Hasta la fecha ello se producía por la vía de proyectos de ley parlamentarios y también de indicaciones parlamentarias, las que alteraban la coherencia global del sistema.

Así, Sergio Molina en su artículo "La planificación y la iniciativa exclusiva del Ejecutivo en materia económica y social” destaca que la reforma constitucional representó un paso significativo para una planificación económica y social más eficaz, y se justificó en el mal uso de las atribuciones parlamentarias del pasado:

"La Reforma Constitucional aprobada (...) no elimina la discusión en el Congreso de las materias que son objeto de ley, sino que limita a los parlamentarios la posibilidad de tomar iniciativas en ciertas materias económicas. (...) Este ultimo aspecto tiene un profundo significado y está en la linea de la argumentación que se ha hecho en párrafos anteriores, en el sentido que los programas económicos y sociales deben cumplir con el requisito esencial de la coherencia y globalidad, y, en consecuencia, no es aceptable ni recomendable para el buen funcionamiento de la administración del pais que se rompa esa coherencia por quienes no tienen la responsabilidad de la administración que, en definitiva, está radicada en el Presidente de la República.

La historia legislativa chilena está plagada de ejemplos en que, por la vía de la indicación a proyectos de ley o la iniciativa parlamentaria (...) se han creado obstáculos graves para el normal desenvolvimiento económico y social del país (...) Lo que sucede es que la presión o presencia de ciertos grupos induce a tomar iniciativas en su favor, sin ponderar debidamente todas las repercusiones que esto puede acarrear. (...) Es difícil para un parlamentario - concluye- negarse a este tipo de demandas porque (...) constituyen grupos con fuerza electoral y politica (...) El ejemplo más claro y trágico se encuentra en la caótica, injusta y dispendiosa legislación sobre seguridad social"ł2.

\footnotetext{
${ }^{42}$ Molina (1970) p. 81.
} 
En este sentido, para el mismo autor, era recurrente que en tiempos pasados se generaran fuertes déficits presupuestarios, ya sea por la aprobación de exenciones tributarias que reducen los ingresos públicos o por la aprobación de gastos sin el financiamiento correspondiente:

¿Qué efectos ha tenido esta actitud legislativa de la cual se han quejado todos los Ministros de Hacienda que se recuerdan? Simplemente, acentuar el déficit crónico del Presupuesto Fiscal con las consecuencias inflacionarias que ha debido soportar toda la población. Lo más paradojal es que, frecuentemente, los mismos que aprueban los mayores gastos fiscales sin financiamiento, son los que después critican a los gobiernos por no haber cumplido con su programa o por no detener el alza de los precios" 43 .

Por otro lado, y como destaca Silva Bascuñán en su artículo de 1970 del debate parlamentario de la reforma, también se busca disminuir el rol de los grupos de interés en el proceso legislativo. En términos actuales, diríamos, se trata de reducir la potencial "captura" al Estado: “(...) otro de sus fundamentos es liberar al Parlamento de los bloques de presión que actúan sobre él, desde distintos niveles y que tienden a obtener normas legales de excepción, que producen un desquiciamiento y anarquía de los planes de acción y sistema preestablecidos" 44 .

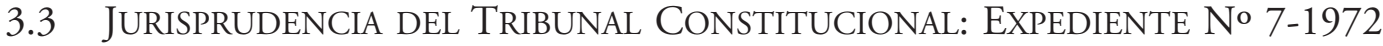

A diferencia de lo ocurrido respecto de la jurisprudencia sobre ideas matrices, en materia de iniciativa exclusiva presidencial el llamado primer Tribunal Constitucional no desarrolló grandes lineamientos conceptuales.

Si bien anunció esta temática en los Expedientes No 2, 6 y 9 de 1972, sería en el No 7 donde pronunciaría algunas ideas, escuetas por lo demás, en este tópico.

En este caso, la cuestión de constitucionalidad relativa a la infracción de la iniciativa exclusiva del Ejecutivo para proponer determinados proyectos de ley, se planteó por el Jefe de Estado, quien reclamó, como se viera anteriormente, por la introducción de una frase agregada al artículo primero del proyecto sobre aguinaldo de fiestas patrias a los trabajadores "a todos los campesinos vivientes en los predios sometidos a proceso de reforma agraria, personas estas que no habían sido consideradas en el Mensaje Presidencial, que quería conceder dicho aguinaldo solo a los trabajadores" ${ }^{25}$.

Sostuvo el Tribunal en los considerandos $4^{\circ}$ y $5^{\circ}$ :

"Que el aguinaldo de Fiestas Patrias a que se refiere el primer inciso del artículo $1^{\circ}$ del proyecto de ley en examen, que por su naturaleza según el léxico es un regalo con motivo de aquellas festividades, que acuerda el Jefe del Estado a través del mecanismo legal, y que dentro del campo juridico y constitucional constituye una asignación o

43 MOLina (1970) p. 82.

44 SilVA BASCUÑ́́N (1970) p. 94.

45 Silva Cimma (2008) p. 75. 
beneficio en dinero que se concede a todos los trabajadores del pais, encuadra precisamente en la facultad privativa que reserva al Presidente de la República el inciso segundo del art. 45 de la Carta Fundamental, al establecer que corresponderá a este, exclusivamente, la iniciativa, entre otras materias, "para fijar o modificar las remuneraciones y demás beneficio pecuniarios del personal de los servicios de la administración del Estado, tanto central como descentralizada", respecto de los trabajadores del sector público, y en las expresiones "y demás beneficios económicos" en lo pertinente al sector privado; y que, si se quiere extenderla por gracia a sectores de no trabajadores, cobra aplicabilidad la frase del precepto en cuestión que señala también como iniciativa exclusiva del Presidente de la República, las leyes que tienen por finalidad "conceder o aumentar por gracia, pensiones u otros beneficios pecuniarios;

Que en tales condiciones forzoso es concluir que la modificación introducida al precitado proyecto de ley por el Senado, en cuanto por ella agregó al primer inciso del artículo $1^{\circ}$ la frase señalada en el considerando tercero de este fallo, es inconstitucional, por contrariar abiertamente el precepto imperativo del inciso del artículo 45 de la Constitución Politica de la República". (considerandos $4^{\circ}$ y 5º).

\subsection{UN CASO PARTICULARMENTE RELEVANTE: REMUNERACIONES Y}

\section{BENEFICIOS LABORALES}

Entre las materias de iniciativa exclusiva presidencial se ubica aquel conjunto sistemático de temas que se agrupan bajo el $\mathrm{N}^{\circ} 4$ del artículo 65, y que se describen de la siguiente forma:

"40.- Fijar, modificar, conceder o aumentar remuneraciones, jubilaciones, pensiones, montepios, rentas y cualquiera otra clase de emolumentos, préstamos o beneficios al personal en servicio o en retiro y a los beneficiarios de montepio, en su caso, de la Administración Pública y demás organismos y entidades anteriormente señalados, como asimismo fijar las remuneraciones minimas de los trabajadores del sector privado, aumentar obligatoriamente sus remuneraciones y demás beneficios económicos o alterar las bases que sirvan para determinarlos; todo ello sin perjuicio de lo dispuesto en los números siguientes;"

Las actuales facultades legislativas del Presidente de la República en materia laboral del sector privado, provienen también desde 1970, con un texto bastante similar al hoy vigente en el artículo $65 \mathrm{~N}^{\circ} 4$ de la CPR.

\subsubsection{El debate doctrinal de la reforma de 1970}

En esta materia, el debate doctrinal es de una riqueza extraordinaria desde una doble perspectiva. En primer lugar, porque nos sirve para contar con elementos de contexto valioso, esto es, ideas económicas y sociales más propias de los 60 y 70, que nuestro actual esquema de economía social de mercado. En segundo lugar, y sin perjuicio de lo anterior, porque los autores que revisaremos están contestes en que las nuevas atribuciones entregadas al Presidente de la República no son ilimitadas. Ello a nuestro 
juicio es de gran relevancia porque, como se verá más adelante, nos permiten conciliar la reforma de 1970 con los nuevos principios inspiradores en materia económico-social garantizados por la Constitución de 1980 .

Silva Bascuñán, en su artículo "El nuevo régimen de iniciativa exclusiva del Ejecuti$v o$ ", reproducido además en su Tratado de Derecho Constitucional, sostiene que es

"original en la reforma de 1970 la disposición que, en relación con la economía colectiva mantenida al margen del control estatal, entrega en forma excluyente al Presidente de la República la iniciativa legal para "fijar los sueldos o salarios minimos de los trabajadores del sector privado, aumentar obligatoriamente sus remuneraciones $y$ demás beneficios económicos o alterar las bases que sirvan para determinarlos. En seguida, en el sector privado, lo que queda sometido a la iniciativa del Presidente es lo que afecta a sus trabajadores... Dentro de tales bases, las leyes reservadas a la exclusividad del Presidente son las que: 1) fijen sueldos o salarios minimos; 2) aumenten obligatoriamente sus remuneraciones y demás beneficios económicos, y 3) alteren las bases que sirvan para determinar tales remuneraciones y beneficios. No quedan, por lo tanto, en el campo reservado a la exclusividad del Presidente, las leyes que fijen los montos, escalas o pautas de remuneración, ni las que determinen remuneraciones máximas, formas de intervención legislativa que no parecen concebibles dentro del principio básico de un campo de economía libre, o sea, de una esfera productiva que quede al margen del control u ordenación directa del Estado. Mientras tanto, no solo la fijación de remuneraciones minimas, que se quieran imponer por ley al sector privado, se comprende dentro del ámbito de la iniciativa propia del Presidente, sino que también las que supongan un aumento obligatorio de todas las remuneraciones $u$ otros beneficios económicos o alteren las bases que estén rigiendo para determinar todos estos beneficios" 46 .

Lo interesante de esta cita es que de ella emerge límite natural a la facultad de aumentar remuneraciones del sector privado por ley. Considerando que este sector económico se encuentra por definición sustraído de "la ordenación directa del Estado", como dice el autor refiriéndose al sector público, entonces no resulta concebible una intervención legislativa que fije u ordene las remuneraciones privadas. No sería compatible con una economía libre, dice Silva Bascuñán.

Es cierto que el límite señalado por este tratadista es bastante extremo: solo operaría si el Ejecutivo y Congreso desean aprobar escalas de remuneraciones para el sector privado, imponer montos o pautas para fijarlas. Pero también es efectivo que la reflexión de Silva Bascuñán prueba que hay un límite constitucional que no resulta lícito trasponer al ejercer esta facultad. Él lo formula como un "principio básico de economía libre”. Tratándose de un constitucionalista, el autor está sin duda subrayando el sustrato constitucional que conforma un sistema económico basado en la libertad.

${ }^{46}$ SILVA BASCUÑÁN (1970) p. 103. 
Un segundo aspecto relevante de las discusiones de la reforma de 1970, y que nos puede servir para los debates actuales, lo constituye la armonización entre la facultad del Presidente de enviar proyectos de ley para aumentar remuneraciones privadas, con el ejercicio del derecho de los trabajadores a la negociación colectiva -actualmente establecido en el inciso quinto del artículo $19 \mathrm{~N}^{\circ} 16$ de la Carta-. Las fuerzas sindicales plantearon este problema ya en 1970, al aprobarse la reforma.

El Ministro de Justicia a la época de la reforma constitucional de 1970, Gustavo Lagos Matus, escribió sobre el asunto en su artículo "Tres Temas centrales de la Reforma Constitucional". Al rebatir a los sindicatos los cargos sobre eventuales restricciones de la reforma al ejercicio de ciertos derechos laborales y sindicales ${ }^{47}$, sostuvo que

“(...) se dijo que atentaba (la reforma constitucional) contra los derechos de los trabajadores la iniciativa exclusiva del Ejecutivo para presentar proyectos de ley que fijaran los sueldos o salarios minimos de los trabajadores del sector privado, que aumentaran obligatoriamente sus remuneraciones y demás beneficios económicos o alteraran las bases que sirven para determinarlos. Cabe señalar que una facultad semejante existe ya hace 26 años con respecto a los sueldos y gratificaciones del personal de la Administración Pública, de las Empresas Fiscales y de las Instituciones Semifiscales. (...) Pero, como es lógico, es el Poder Ejecutivo el único responsable de medir la influencia que tales medidas pueden tener en el desfinanciamiento del Presupuesto Nacional, en el aumento de la inflación y en la imposición de nuevos tributos que son pagados por todo el pais. (...) Este régimen se hace extensivo ahora al sector privado, pero con una limitación importante: se refiere únicamente a los sueldos y salarios minimos de los trabajadores y al aumento obligatorio de sus remuneraciones (...) Ello significa que subsisten integramente todas las disposiciones relativas a la presentación de pliegos de peticiones, a la negociación colectiva, a la huelga, a las comisiones mixtas de sueldos, a las comisiones existentes para fijar los salarios minimos agrícolas, a los contratos individuales y colectivos de trabajo, etc. La facultad del Poder Ejecutivo en esta materia tendrá, por lo tanto, un carácter supletorio y racionalmente solo se ejercerá si, a través de los mecanismos indicados, el nivel de remuneraciones del sector privado no alcanza limites satisfactorios. El sistema no vulnera, por lo tanto, los derechos de los trabajadores, sino que crea un instrumento más, de gran flexibilidad, para llegar al estableci-

\footnotetext{
47 En esta materia opinó: "Durante la tramitación de la Reforma, diversos sectores politicos iniciaron una campaña de protesta calificando al proyecto de antigremial y contrario a los intereses de los trabajadores (...) Las críticas fueron dirigidas a los artículos que establecían que el Congreso podría delegar ciertas facultades legislativas en el Presidente de la Republica, y que correspondería al Poder Ejecutivo la iniciativa exclusiva para proponer proyectos de ley en determinadas materias de orden económico y social. Las criticas a estas disposiciones se resumian diciendo que el Congreso Nacional quedaba privado de todo poder efectivo y se reducía a una mera entidad decorativa, que la reforma atentaba contra los derechos de los trabajadores al suprimir el derecho de huelga y la posibilidad de presentar pliegos de peticiones, y que el Presidente de la República podría modificar por simple decreto los sistemas previsionales. En suma, se agregaba, el pais quedara reducido al inmovilismo en cuanto a los derechos económicos y sociales de los trabajadores, ya que solo el Presidente de la República tendrá la iniciativa para mejorar sus derechos". Ver LAGOS (1970) p. 61.
} 
miento de remuneraciones adecuadas para los empleadores particulares y los obreros del sector privado" 48 .

Este valiosísimo antecedente histórico y doctrinario aporta certeros elementos de interpretación. Ellos son: que el derecho de los trabajadores a la negociación colectiva queda inalterado y plenamente resguardado con motivo de la reforma constitucional de 1970; y que la facultad Presidencial y del Congreso de imponer sueldos mínimos y de aumentar las remuneraciones al sector privado, ya tenía en 1970 un carácter supletorio al mecanismo de la negociación colectiva y era excepcional, al ejercerse solo "si a través de los mecanismos indicados" los sueldos privados "no alcanzan niveles satisfactorios".

Finalmente, un último aporte lo encontramos en el trabajo del profesor Guillermo Piedrabuena -que años después sería Fiscal Nacional-, quien analiza detalladamente en su libro "La Reforma Constitucional”, los principales alcances de la Ley 17.284 en lo pertinente a la iniciativa exclusiva del Presidente en la normativa laboral del sector privado.

Para el autor,

"esta Facultad del Ejecutivo para proponer los sueldos y salarios minimos del sector privado de manera alguna obstaculiza al derecho de negociación colectiva de los trabajadores para ganar remuneraciones mayores, como lo demuestra la historia fidedigna de la ley (...) Interrogado el Ministro Andrés Zaldivar en el seno de la Comisión de Legislación de la Cámara de Diputados, por el diputado Maira, así lo afirmó: “(...) Lo que se pretende en el texto es nada más que la iniciativa de la politica de remuneraciones, o sea, que la fijación de los porcentajes para la gente que no está sometida a negociación colectiva, sea hecha por el Ejecutivo a través de su propia iniciativa y que no la tenga el Parlamento (...) A similar conclusión llegó el primer informe de la Comisión de Legislación de la Cámara, que dejó constancia que interesaba "destacar que quedó claramente establecido en el seno de la Comisión que la circunstancia de otorgar la iniciativa privada al Ejecutivo para los proyectos de ley sobre reajuste de remuneraciones del sector privado o la fijación de salarios minimos, no obsta, en modo alguno, a la posibilidad de la negociación colectiva directa entre los sectores asalariados y empresariales. Ella queda abierta, y la iniciativa presidencial regirá para aquellos sectores que están privados de dicha posibilidad (...)Habría que agregar que también rige la iniciativa presidencial para la fijación de salarios o sueldos minimos de los sectores que pueden negociar colectivamente y no lo hacen, porque la última frase del informe no da a entender claramente esta posibilidad (...) También la Comisión de Legislación del Senado, dejó constancia en su primer informe a la Sala que "como lo ha expresado el Ejecutivo, tanto el texto de esta frase cuanto el propósito del Gobierno, se orientan a que la restricción no se aplique, en caso alguno, al derecho de negociación colectiva de los trabajadores del sector privado para lograr, por esa vía, remuneraciones mayores que las determinadas por la vía legal" 49.

${ }^{48}$ LAGOS (1970) pp. 64-65.

49 Piedrabuena (1970) pp. 110-11. 
Piedrabuena refuerza decididamente entonces el carácter supletorio de la ley en los reajustes de salarios del sector privado, para el aumento de sus remuneraciones. La iniciativa del Presidente de la República operaría solo para los trabajadores que están privados de la posibilidad de negociar colectivamente.

\subsubsection{El debate en perspectiva: armonización con nuevos principios y derechos}

La Constitución de 1980 mantiene en términos gruesos la órbita de materias que quedaron de iniciativa exclusiva del Presidente en la Constitución de 1925 luego de la reforma de 1970 .

Preparándose la actual Carta, el informe de la Comisión de Estudio para la Nueva Constitución (CENC), también llamada comisión Ortúzar, expresa que

"El anteproyecto otorga, asimismo, especiales atribuciones al Presidente de la República para ejercer la administración económica del pais [...] Al efecto como se verá al tratar de las atribuciones de carácter legislativo del Presidente de la República-, amplía considerablemente la iniciativa exclusiva del Presidente de la República en todas aquellas materias administrativas, económicas, financieras, previsionales y otras que, en general, pueden importar gastos al erario" 50.

Ello en lo general: hay un reforzamiento de la iniciativa exclusiva.

Un análisis superficial de este fragmento del trabajo de la CENC podría llevar a concluir que el Presidente de la República, en la actualidad y bajo la Constitución de 1980, puede utilizar estas atribuciones bajo las mismas condiciones establecidas en la Carta de 1925 en diversas áreas de impacto económico-social (e.g., en materia de remuneraciones privadas).

Un análisis más riguroso arroja, sin embargo, otra conclusión. El elemento sistemático de interpretación ${ }^{51}$-tantas veces invocado por el Tribunal Constitucional-52 lleva irrefutablemente a una inferencia distinta. Es imposible interpretar aisladamente las atribuciones económicas entregadas al Presidente de la República en el artículo 65, y llegar a la misma conclusión hoy, en 2008, que si el resto de los ciento diez artículos del Código Supremo de 1925 estuvieran aún vigentes.

En efecto, el elemento sistemático obliga a construir una interpretación razonable, que permita conciliar el artículo 65 con principios, derechos, garantías inexistentes en la Carta de 1925, pero vigentes en el día de hoy.

En especial, las atribuciones del Presidente en materia legislativa de impacto económico-social debe armonizarse por ejemplo con:

a) El principio de subsidiariedad del artículo $1^{\circ} \mathrm{CPR}$, que solo permite al Estado actuar supletoriamente al actuar privado, y que forma parte de la nueva sección axiológica, valórica de la actual Carta Máxima;

\footnotetext{
50 SilVA BASCUÑÁN (2000) p. 111.
} 
b) El derecho a la libre contratación (art. $19 \mathrm{~N}^{\circ} 16$ ), que es una novedad en la Constitución de 1980, puesto que su predecesora solo garantizaba el derecho al trabajo $^{53}$;

c) El derecho a desarrollar cualquier actividad económica lícita (art. 19 N²1), también derecho enteramente nuevo, cuyo objeto es precisamente otorgar protección al emprendimiento privado y su marco básico, uno de cuyos elementos esenciales es el trabajo;

d) El reforzamiento del derecho de propiedad y en especial el de propiedad incorporal (sobre contratos), que, aun con las limitaciones de la función social (art. 19 $\mathrm{N}^{\circ} 24$ inciso segundo), pretendió reforzarse y "acorazarse" por la CENC y su Subcomisión de Propiedad, presidida por don José María Eyzaguirre, quien presentó el informe con las conclusiones de su investigación en la sesión $148^{\circ 54}$;

e) El nuevo Orden Público Económico y su inspiración constitucional, reflejado en las actas de la CENC en sus sesiones N³88 y siguientes. Al respecto, considérese la observación del Presidente de la Comisión, don Enrique Ortúzar, quien defiende la idea de incorporar en el Texto Magno las bases filosóficas del nuevo sistema económico:

"El señor ORTÚZAR (Presidente) estima que no se trata de consagrar una politica económica, sino de establecer ciertos principios fundamentales sobre el orden público económico, los cuales, en el fondo, emanan de la filosofía de la nueva institucionalidad, fundamentada esencialmente en la libertad del hombre y en la iniciativa que deriva de su capacidad creadora, que debe ser respetada por el Estado" 55.

Esta forma de interpretar el esquema económico constitucional no es solo un dato histórico, generado hace 35 años, sino también vigente en la actualidad en lo básico. Por ejemplo, el Tribunal Constitucional ha ratificado, en sentencia rol 513-2006, fallada el 2 de enero de 2007, caso "Aprovechamiento de Aguas", que:

"Asimismo de la consulta de las actas de la Comisión de Estudio de la Nueva Constitución se puede apreciar que al consagrar este derecho los comisionados tuvieron en

\footnotetext{
51 ZAPATA (2002) p. 48.

52 En esta línea se inscriben los Ministros Bertelsen, Correa y Fernández en una prevención en fallo reciente e invocando los precedentes en esta materia: “(...) recogido en múltiples oportunidades por reiterada doctrina de esta misma Magistratura acerca de que la inteligencia que se dé a un precepto de la Carta Fundamental debe resultar armónico con las restantes normas del mismo cuerpo, de modo de asegurar la efectiva vigencia de todos sus preceptos (Véase, por ejemplo, las sentencias roles 309, 325, 383, 392, 396 y 596)". Ver STC Rol No 815, de 19 de agosto de 2008, considerando $4^{\circ}$.

53 La Constitución de 1925 lo garantizaba de la siguiente forma: "Ninguna clase de trabajo o industria puede ser prohibida, a menos que se oponga a las buenas costumbres, a la seguridad o a la salubridad pública, o que lo exija el interés nacional y una lei lo declare asi".

54 ACTAS OfiCiales de la COMisión CONSTITUyente, sesión $148^{\circ}$, p. 21.

55 ACTAS OfICIALES DE LA COMISIÓN CONSTITUYENTE, sesión 400º celebrada en miércoles 12 de julio de 1978, en materia de Orden Público Económico cuando se discutía la normativa del Banco Central. Página 3.160.
} 
vista, como un elemento vertebral del nuevo orden público económico que la Constitución se proponía instituir, la conveniencia de que los particulares tuvieran preeminencia frente al Estado en cuanto a ser titulares del dominio de los bienes situados en el territorio nacional, lo que es coherente con el rol subsidiario que el nuevo régimen jurídico-político asignó al Estado en materia económica". (considerando 28²)

\section{CONCLUSIONES}

Este trabajo se propuso demostrar que el presidencialismo chileno no tiene su origen pleno en la Constitución de 1980, sino en la reforma constitucional que se introdujo en 1970 a la Carta de 1925.

Para ello analizamos aquí dos instrumentos cruciales en la supremacía legislativa del Presidente de la República: la iniciativa legislativa exclusiva presidencial, y la prohibición de las indicaciones y enmiendas que se aparten de las ideas matrices de un proyecto de ley.

Hemos demostrado que la reforma constitucional de 1970 tuvo el propósito, con decisión política y discusiones jurídico-institucionales ricas en argumentos, de inhibir una serie de prácticas legislativas estimadas impropias, que estaban dañando los cimientos mismos de nuestra democracia.

Impresionan los debates de la época, y más todavía, las sentencias del Tribunal Constitucional de 1972 recaída sobre estas materias -la operacionalización de las nuevas normas constitucionales-, todo lo que fue relevante para establecer una nueva manera de entender el proceso legislativo en Chile, reforzando el poder relativo del Ejecutivo.

En síntesis, la Constitución de 1980 vino a ratificar todo lo obrado en este ámbito por el constituyente de 1970. Entonces, si hemos de afirmar que nuestro régimen de gobierno es un presidencialismo reforzado o constitucionalmente hipertrofiado -con la formidable primacía legislativa del jefe de Estado- hemos también de acordar que los primeros pilares de este sistema preexisten a la carta de 1980, al ser diseñados en la reforma constitucional de 1970.

\section{BIBLIOGRAFÍA CITADA}

ACKERMAN, Bruce (1991): We the people (1): Foundations (Harvard, Harvard University Press) 369 pp.

ACKerman, Bruce (1989): “Constitutional Politics/Constitutional Law”, Yale Law Journal, Vol. 9: pp. 521-536.

Bravo LiRA, Bernardino (1986): Régimen de Gobierno y Partidos Politicos en Chile 19241973 (Santiago, Editorial Jurídica de Chile, 2a ed.) 180 pp.

BuchHeister Rosas, Axel y Soto Velasco, Sebastián (2005): “Ideas matrices en los proyectos de ley: inconsistencias del Tribunal Constitucional” en: VV.AA. Sentencias Destacadas 2004 (Santiago, Ediciones Libertad y Desarrollo) pp. 125-156.

CeA Egaña, José Luis (2008): Derecho Constitucional Chileno (Santiago, Ediciones Universidad Católica de Chile, 2a ed.) tomo II. 
Cumplido, Francisco (1970): “La especificación de la Ley” en FrEI, Eduardo, Sergio Molina, Enrique Evans, Gustavo LagOS, Alejandro Silva y Francisco CuMPlido: La Reforma Constitucional de 1970 (Santiago, Editorial Jurídica de Chile) pp. 179-195.

Discurso del Presidente Frei Montalva sobre Reformas Constitucionales. 30 de diciembre de 1969 (1970). En Guillermo Piedrabuena Richards: La Reforma Constitucional. Historia de la Ley 17.284, sus principales alcances y posición de los partidos politicos (Santiago, Ediciones Encina Ltda.) pp. 167-175 (Anexo No 3).

EDWARDS VIVES, Alberto (1976): La Fronda Aristocrática (Santiago, Editorial del Pacífica, $8^{\mathrm{a}}$ ed.) $320 \mathrm{pp}$.

Evans DE LA CUADRA, Enrique (1999): Los Derechos Constitucionales (Santiago, Editorial Jurídica de Chile) tomo III.

FERMAndois VÖHringer, Arturo (2006): Derecho Constitucional Económico (Santiago, Ediciones Universidad Católica de Chile) tomo I.

Frei Eduardo, Sergio Molina, Enrique Evans, Gustavo Lagos, Alejandro Silva Y Francisco Cumplido (1970): La Reforma Constitucional de 1970 (Santiago, Editorial Jurídica de Chile) 300 p.

GRAFTON, John (2000): The Declaration of Independence and Other Great Documents of American History, 1775-1865 (New York, Dover) 96 pp.

Kramer, Larry (2004): The People Themselves: Popular Constitutionalism and Judicial Review (New York, Oxford University Press) 363 pp.

KrAMER, Larry (2001): "Foreword: We the Court", Harvard Law Review, Vol. 115: pp.4-169.

MAdisOn, James; HAMILTON, Alexander y JAY, John (1987): The federalist papers (London, Penguin classics) 517 pp.

Molina, Sergio: "La planificación y la iniciativa exclusiva del Ejecutivo en materia económica y social' (1970) en: FreI, Eduardo Sergio MOLINA, Enrique EvanS, Gustavo.

Lagos, Alejandro Silva y Francisco Cumplido: "La Reforma Constitucional de 1970" (Santiago, Editorial Jurídica de Chile) pp. 77-78.

Nogueira AlCAlá, Humberto (1984): "Presidencialismo democrático y presidencialismo autoritario. El artículo 32 No 5 de la Constitución de 1980 y la clasificación de la forma de gobierno", Revista Chilena de Derecho, vol. XI No 2-3: pp. 317-323.

Piedrabuena Richards, Guillermo (1970): La Reforma Constitucional. Historia de la Ley 17.284, sus principales alcances y posición de los partidos políticos (Santiago, Ediciones Encina Ltda.) 271 p.

Primer informe de la COMisión de Constitución, Legislación, Justicia y Reglamento Del Senado, de 1 de septiembre de 1969 (1970). En Piedrabuena RICHARDS, Guillermo: La Reforma Constitucional. Historia de la Ley 17.284, sus principales alcances y posición de los partidos politicos (Santiago, Ediciones Encina Ltda.) pp. 180-237 (Anexo No 6).

SILVA BASCUÑÁN, Alejandro, "El nuevo régimen de iniciativa exclusiva del Ejecutivo" En FreI, Eduardo Sergio Molina, Enrique Evans, Gustavo Lagos, Alejandro Silva y Francisco Cumplido: "La Reforma Constitucional de 1970” (Santiago, Editorial Jurídica de Chile) pp. 89-107. 
Silva BASCUÑÁN, Alejandro (1997): Tratado de Derecho Constitucional (Santiago, Editorial Jurídica de Chile, 2a ed.) tomo III.

Silva BASCUÑÁn, Alejandro (2000): Tratado de Derecho Constitucional (Santiago, Editorial Jurídica de Chile, 2a ed.) tomo VII.

Silva Cimma, Enrique (2008): El Tribunal Constitucional de Chile (1971-1973) Cuadernos del Tribunal Constitucional, No 38: 178 pp.

TAPIA VALDÉS, Jorge (1960): La Técnica Legislativa (Santiago, Editorial Jurídica de Chile) $102 \mathrm{p}$.

Verdugo Marinkovic, Mario y Pfeffer urquiaga, Emilio (2005): Derecho Constitucional (Santiago, Editorial Jurídica de Chile) Tomo I.

Zapata Larraín, Patricio (2002): La Jurisprudencia del Tribunal Constitucional (Santiago, Universidad Andrés Bello) 200 pp.

\section{NORMAS CITADAS}

Ley No 17.284, Modifica regulación del derecho a sufragio y derecho a la protección del trabajo. Agrega requisito para ser parlamentario. Modifica el régimen de salida del territorio del Presidente de la República y de los Ministros de Estado, el procedimiento de tramitación de las leyes y regula la delegación de la potestad legislativa. Agrega el Tribunal Constitucional. Modifica el procedimiento de reforma constitucional y establece facultad para dictar texto refundido de la Constitución. Diario Oficial, 23 de enero de 1970.

Ley No 20.281, Modifica el código del trabajo en materia de salarios base. Diario Oficial, 21 de julio de 2008.

\section{JURISPRUDENCIA CITADA}

Inconstitucionalidad, de diversas normas del proyecto de ley de presupuesto para el año 1972, publicada en el Diario Oficial Ley No 28.210, 25 de marzo de 1972, Sentencia del Tribunal constitucional (requerimiento de constitucionalidad), 19 de enero de 1972, expediente No 1-1972, Mensaje a: RodríGueZ SteHn, Camila. 23 de octubre de 2008 [consultado el 29 de diciembre de 2008]. Comunicación personal.

Inconstitucionalidad, artículo $1^{\circ}$ del proyecto de ley sobre aguinaldo de fiestas patrias, publicada en el Diario Oficial Ley No 28.358, 21 de septiembre de 1972, Sentencia del Tribunal Constitucional (requerimiento de constitucionalidad), 12 de septiembre de 1972, expediente No 7-1972. Mensaje a: Rodríguez Stehn, Camila. 23 de octubre de 2008 [consultado el 29 de diciembre de 2008]. Comunicación personal.

Inconstitucionalidad, artículos $2^{\circ}$ y $3^{\circ}$ del proyecto de ley que otorga permiso de tráfico aéreo para operar la ruta entre santiago y las provincias de Aisén y Magallanes, publicada en el Diario Oficial Ley No 28.395, 06 de noviembre de 1972, Sentencia del Tribunal constitucional (requerimiento de constitucionalidad), 26 de octubre de 1972, expediente No 9-1972. Mensaje a: RodrígueZ SteHn, Camila. 23 de octubre de 2008 [consultado el 29 de diciembre de 2008]. Comunicación personal. 
Inconstitucionalidad, proyecto de ley que modifica la Ley General de Bancos y otros textos legales, denominado Información sobre Créditos de Consumo, Sentencia Tribunal Constitucional (requerimiento de constitucionalidad), 26 de septiembre de 1997, rol No 259-1997 [fecha de consulta 25 de diciembre de 2008]. Disponible en: <http://www.tribunalconstitucional.cl/index.php/sentencias/download/pdf/359>

Inconstitucionalidad, proyecto de ley que modifica el régimen de jornada escolar completa diurna y otros cuerpos legales, Sentencia Tribunal Constitucional (requerimiento de constitucionalidad) 14 de junio de 2004, rol No 410-2004 [fecha de consulta 25 de diciembre de 2008]. Disponible en: <http://www.tribunalconstitucional.cl/> index.php/sentencias/download/pdf/210>

Inconstitucionalidad, artículo $5^{\circ}, \mathrm{n}^{\circ} 13$, del proyecto de ley que modifica el régimen de jornada escolar completa diurna y otros cuerpos legales, Sentencia Tribunal Constitucional (requerimiento de constitucionalidad), 26 de julio de 2004, rol No 413-2004 [fecha de consulta 29 de diciembre de 2008]. Disponible en: <http:// www.tribunalconstitucional.cl/index.php/sentencias/download/pdf/207>

Inaplicabilidad por inconstitucionalidad, inciso segundo del artículo primero transitorio de la Ley No 20.017, publicada en el Diario Oficial el 16 junio de 2005, Sentencia Tribunal Constitucional (recurso de inaplicabilidad por inconstitucionalidad), 2 de enero de 2007, rol No 513-2006 [fecha de consulta 25 de diciembre de 2008]. Disponible en: <http://www.tribunalconstitucional.cl/index.php/sentencias/download/pdf/142>

Inconstitucionalidad, artículo único, número tres, del Proyecto de Ley modificatorio de la Ley No 20.084, que establece un sistema de responsabilidad de los adolescentes por infracciones a la ley penal, en la parte en que dicha norma modifica el artículo 23 No 1 del citado cuerpo legal, publicada en el Diario Oficial el 7 de diciembre de 2005, Sentencia Tribunal Constitucional (recurso de inaplicabilidad por inconstitucionalidad), 13 de junio de 2007, rol No 786-2007 [fecha de consulta 25 de diciembre de 2008]. Disponible en: <http://www.tribunalconstitucional.cl/index.php/sentencias/download/pdf/21> 
